\title{
A possible contribution to improving the therapeutic potentials of Babor's Typology of Alcohol Dependent Patients
}

\author{
Uma possível contribuição para incrementar o potencial terapêutico \\ da classificação Tipo A/Tipo B de Dependentes de Alcoólicos
}

Mário Sérgio Ribeiro', Luiz Cláudio Ribeiro2, Rafael Augusto Ferreira³

\section{ABSTRACT}

Objective: The objective of this study was to replicate Babor's Typology and to explore clinical features related to personality traits that may underlie this classification, in order to improve its therapeutic possibilities. Methods: Observational prospective study on a group of 273 male alcoholics. After a replication of Babor's variables, Cluster Analysis, Chi-Square - applied on clinical variables related to a Lappda Tipology - and Kappa tests were performed. Results: The study identified two distinct clusters that held similar features to those described for the Type A/Type B classification. Besides presenting a lower socio-economic situation, Cluster 2 patients were associated with higher vulnerability and severe clinical features and also differed from Cluster 1 in their response to treatment. These replicated clusters retained connections and also differences in relation to the variables derived from the Lappda Typolo-

\section{Keywords}

Alcoholism, typology, diagnosis, cluster analysis, alcoholism treatment.

gy. Conclusion: Considering that each of the two replicated clusters seem to be associated to different personality traits - according to their correlations to the affective, cognitive and behavioral dimensions brought forward by the Lappda Typology - it is acceptable that this study may contribute to the development of more comprehensive and effective therapeutic strategies specifically tailored to target more specific personality traits of these subgroups of alcoholic patients.

\section{RESUMO}

Objetivo: O objetivo deste estudo foi replicar a tipologia do Babor e explorar características clínicas relacionadas a traços de personalidade que podem estar subjacentes a essa classificação, a fim de melhorar suas possibilidades terapêuticas. Métodos: Estudo observacional prospectivo em um grupo de 273 alcoolistas masculinos. Depois de uma replicação das variáveis de Babor, foram realizados Análise de Cluster, testes de Qui-quadrado — aplicados em variáveis clínicas relacionadas com uma tipologia desenvolvida pelo Lappda - e testes Kappa. Resultados: $O$ estudo identificou dois clusters distintos que mantiveram características semelhantes àquelas descritas na classificação Tipo A/Tipo B. Além de apresentar uma pior situação socioeconômica, os pacientes do Cluster 1 foram associados a maior vulnerabilidade e a características clínicas de maior gravidade; e também diferiram do Cluster 2 em sua res-

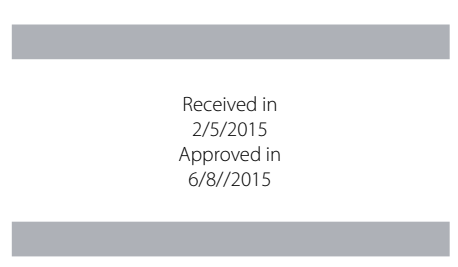

DOI: $10.1590 / 0047-2085000000079$
1 Federal University Federal of Juiz de Fora (UFJF), Department of Clinical Medicine; Laboratory of Researches on Personality, Alcohol and Drugs (Lappda-UFJF).

2 UFJF, Department of Statistics.

3 UFJF; Lappda-UFJF.

Address for correspondence: Mário Sérgio Ribeiro

Rua Severino Meireles, 325/902, São Mateus

36025-040 - Juiz de Fora, MG, Brazil

Telephone: 55 (32) 3211-3833

E-mail:mariosribeiro@acessa.com 


\section{Keywords}

Alcoolismo, tipologia, diagnóstico, análise de cluster, tratamento do alcoolismo posta ao tratamento. Esses clusters replicados mantiveram conexões e também diferenças em relação às variáveis derivadas da tipologia do Lappda. Conclusão: Considerando que cada um dos dois clusters replicados parece estar associado a diferentes traços de personalidade - de acordo com suas correlações a dimensões afetivas, cognitivas e comportamentais identificadas pela tipologia Lappda — é aceitável que este estudo possa contribuir para o desenvolvimento de estratégias terapêuticas mais abrangentes e eficientes, especificamente dirigidas a traços da personalidade mais específicos desses subgrupos de pacientes alcoolistas.

\section{INTRODUCTION}

Alcohol dependence syndrome (ADS) is a complex concept that reflects a range of neurobiological, cognitive and behavior symptoms. Environmental and genetic features contribute both to the pattern of alcohol consumption and to the risk of ADS!

Patients with alcohol related disorders (ARD) differ in many traits, such as age of onset of heavy drinking (early or late), patterns of drinking (continuous or binge), rate of alcohol metabolism, susceptibility to intoxication, presence or absence of comorbid psychiatric illness and rapidity of progression to medical problems².

The heterogeneity of clinical presentation of ARD - which include relevant differences according to their gender ${ }^{3}$ - has justified efforts to classify them into subtypes that refine diagnosis and may give support to tailored treatment designs and better established prognosis ${ }^{4-6}$.

Typological systems derive either from a priori theories or previous clinical and epidemiological studies. Typologies may have been developed under single or multidimensional criteria. They may derive different number of subtypes and are influenced by characteristics of the samples used in their construction; but are expected to help to elucidate the etiologic mechanisms that lead to the development of the different subtypes ${ }^{7,8}$. Despite the many similarities between typologies developed up to date, they have not yet fulfilled criteria for an ideal classification?,10.

Two well recognized typologies of alcoholism are those established by Cloninger and Babor ${ }^{11-13}$ : both indicate binary models of alcoholism and are still widely use in clinical and research settings ${ }^{14}$.

Babor's typology identified two subgroups of alcoholic patients - described as Type A and Type B - that reflect the two phenotypes most often identified by several researchers $^{11}$ : a subgroup of lower vulnerability and clinical severity and another with more severe features. The Type A alcoholics were characterized as being more conservatives - i.e. less prone to experiences and novelties. Their problems with alcohol would have a later onset; they would also present lower rates of ADS, of physical and social consequences related to alcoholic consumption, of psychological comorbidity and of family and labor related problems; they also present a slower progression of the disorder and have a better prognosis. Alternatively, Type B alcoholic patients were described as more prone to experience and novelty, having higher levels of anxiety and earlier onset of alcohol problems. They would have higher rates of ADS, of other substance abuse and psychological comorbidity. Physical and social consequences are specially correlated to Type B alcoholic patients that also present a faster clinical progression and poorer prognosis ${ }^{4,9,11}$.

Even though Babor's binary typology of alcoholism has been repeatedly used in researches in this field, it has not yielded consistent results as far as its clinical and epidemiological usefulness, as expected of medical typologies ${ }^{4,15-19}$. It has been suggested that future typological research should strive to identify the limitations of actual classifications, highlight their differences and explore the consistencies they might share, to move towards a more effective routine clinical use $\mathrm{e}^{2,20}$.

The objective of this study was to replicate Babor's Typology and to explore clinical features related to personality traits that may underlie this classification of ADS patients, in order to improve its therapeutic possibilities.

\section{METHODS}

Observational prospective study that used the medical records of male ADS patients referred to an alcohol and drugs outpatient treatment program of the public health system of the city of Juiz de Fora, state of Minas Gerais, Brazil. The study was approved by the local ethics committee and used the clinical records of patients that had their first appointment between October 1997 and December 2005. The assessment and treatment routines of this program have been previously presented and discussed ${ }^{13,15,21}$.

Briefly, patients' evaluations were undertaken by the multiprofessional team responsible for their everyday assistance - which included one Psychiatrist, 2 Psychologists, a Psychiatric Nurse, a General Practitioner and two Medical Residents, all under the supervision of the main author of this paper. These professionals used specific semi-structured and structured instruments, some of which developed according to empirical evidences of relevance to the multidimentional assessment 
of ADS patients'. Besides the Minnesota Multiphasic Personality Inventory (MMP|22,23), the complete assessment battery encompassed the following domains: 1) Sociodemographic description; 2) Identification of consumption patterns; 3) Identification of phenomena that triggered or reinforced alcohol consumption; 4) Pacients attitudes in face of their problems; 5) Identification of physical or mental complications; 6) Physical examination; 7) Psychopatological examination; 8) Final Diagnose (including comorbidity); 9) Delimitation of macro and microsocial consequences. The data produced during these evaluations were included in a eletronic bank and followed on by auxiliary researchers. Psychiatric diagnoses were established on clinical basis, according to the criteria of the International Classification of Diseases (ICD-10).

Departing from the 303 male patients previously studied - namely during the construction of the binary Lapdda Typology, recently presented, by means of Correspondence, cluster and heuristic analysis ${ }^{12}-, 30$ patients whose medical records did not have enough information for this proxy replication of Babor's Typology were excluded and the records of 273 patients were analyzed for this study.

All variables used in this study derived from the assessment instruments used in the outpatient program or were generated by combinations of the clinical data ${ }^{13,15,21}$. A few adjustments were necessary so that available clinical data could represent Babor's variables as strictly as possible: all these adaptations are well described in table 1, where we indicate some that were modified regarding our previous study on Babor's Tipology ${ }^{15}$. Following an a priori decision to work with binary outputs, categorical variables were regrouped into two categories and the continuous ones were classified as above or below the median for this group of 273 patients (see Table 2). As the assessment instruments did not include variables related to "Childhood Disorder" and "Lifetime Severity" of alcohol problems, 15 out of the 17 Babor's variables were finally included in this study.

Cluster Analysis (CA) was performed on these 15 variables using the K-means, pairwise option, classify only method and indicating a two cluster solution. Considering the objectives of the study Chi-Square Tests were performed: a) between the identified clusters and 12 socio-demographic variables; b) between these two clusters and the 15 replicated variables; and c) between these clusters and variables identified on the construction of the Lappda typology. Finally, we tested the agreement between these two clusters and those derived from our previous study ${ }^{12}$ using the Kappa ratio.

Table 1. Variables used in Babor's original study and adaptations assumed in this replication

\begin{tabular}{|c|c|}
\hline Variables used in Babor's original study & Adaptations assumed in this replication \\
\hline \multicolumn{2}{|r|}{ Premorbid risk factors } \\
\hline 1. Familial Alcoholism* & One of the parents being an alcoholic (Yes/No) \\
\hline 2. Childhood Disorder & No possible adaptation \\
\hline 3. Bipolar Character Dimensions (MacAndrew Scale of MMPI) & Median score of MMPI MacAndrew Scale ${ }^{21,22}$ \\
\hline 4. Onset of Problem Drinking* & $\begin{array}{l}\text { Median of the average for two age bench-marks: a) "when drinking became a problem"; e b) "when he(she) increased the } \\
\text { amount of alcoholics regularly used" }\end{array}$ \\
\hline 5. Alcohol Consumption & Median of the number of drinks consumed per week \\
\hline \multicolumn{2}{|r|}{ Pathological Use of Alcohol and Other Substance } \\
\hline 6. Relief Drinking* & ICD-10 criteria ( for ADS and/or DSM-IV criteria 2B (Yes/No) \\
\hline 7. Alcohol Dependence Syndrome & Presence of ADS for DSM-IV and CID-10 criteria (Yes/No) \\
\hline 8. Benzodiazepine Use & Use of medication for anxiety, irritability, or to sleep (Yes/№) \\
\hline 9. Polydrug Use & Use of cocaine, marijuana, hypnotics, solvents, hallucinogens, opiates or stimulants (Yes/No) \\
\hline \multicolumn{2}{|r|}{ Chronicity and Consequences of Drinking } \\
\hline 10. Medical Conditions* & Medical Diagnosis indicated in Clinical Chart (Yes/No) \\
\hline 11. Physical Consequences & $\begin{array}{l}\text { Median of the sum of clinical symptoms (sexual problems, nausea, vomits, diarrhea, heartburn, abdominal pain, jaundice, } \\
\text { weakness, weight loss, anemia, cough, expectoration, fever, dyspnea, edema, dysphagia, hypertension, skin lesions, pain in } \\
\text { lower limbs, paresthesia, cramps, unsteadiness, amnesia, syncope, seizures, sweating, trembling, nervousness and insomnia) } \\
\text { listed in medical chart }\end{array}$ \\
\hline 12. Social Consequences & $\begin{array}{l}\text { Median of the sum of social consequences possibly related to drinking problems (with family, other people and institutions; } \\
\text { delay, faults, dismissal and use at work; verbal and physical aggression) listed in medical chart }\end{array}$ \\
\hline 13. Lifetime Severity & No possible adaptation \\
\hline 14. Years of Heavy Drinking & Median of time elapsed since the onset of problems with drinking \\
\hline \multicolumn{2}{|r|}{ Psychiatric Symptoms } \\
\hline 15. Depressive Symptom Count & Median score for MMPI D Scale 21,22 \\
\hline 16. Antisocial Personality Symptom Count & Median score for MMPI PD Scale \\
\hline 17. Anxiety Severity (Taylor Manifest Anxiety Scale of MMPI) & Median score for MMPI Taylor Scale (Median $=24,5$ ) \\
\hline
\end{tabular}

* Variables that were modified regarding our previous study ${ }^{12}$ 
Table 2. Socio-demographic characterization of Identified Clusters

\begin{tabular}{|c|c|c|c|c|}
\hline Variables & $\begin{array}{c}\text { Total } \\
(\mathrm{n}=273) \\
(\%)\end{array}$ & $\begin{array}{c}\text { Cluster } 1 \\
(\mathrm{n}=96) \\
(\%)\end{array}$ & $\begin{array}{c}\text { Cluster 2 } \\
(n=177) \\
(\%)\end{array}$ & p-value \\
\hline Age above the median* & 50.7 & 50.5 & 50.8 & 0.960 \\
\hline Race/ethnicity: described as "white" & 72.6 & 73.4 & 72.1 & 0.819 \\
\hline Married or living as if married & 53.1 & 40.0 & 50.6 & 0.096 \\
\hline Have children & 77.6 & 77.9 & 77.5 & 0.934 \\
\hline Catholics & 80.1 & 86.3 & 76.7 & 0.059 \\
\hline Attend religious service & 61.2 & 64.9 & 59.1 & 0.362 \\
\hline Low Schooling' & 81.5 & 82.1 & 81.3 & 0.863 \\
\hline Employed & 32.0 & 39.8 & 27.8 & 0.046 \\
\hline Economically independent & 53.5 & 65.3 & 47.2 & 0.004 \\
\hline Breadwinner & 28.8 & 37.0 & 24.6 & 0.034 \\
\hline Low personal income ${ }^{2}$ & 55.1 & 33.0 & 51.5 & 0.004 \\
\hline Low familial income ${ }^{3}$ & 57.7 & 55.4 & 60.5 & 0.449 \\
\hline
\end{tabular}

Median of 43 (media 42.7; minimum 19 and maximum 69).

'Up to eight grade of elementary school.

${ }^{2}$ Maximum of 1 Brazilian Minimum Wage (approximately US\$ 300 at the time).

${ }^{3}$ Maximum of 3 Brazilian Minimum Wages.

\section{RESULTS}

In average, patients included in this study were 43 years old (media 42.7; minimum 19; and maximum 69), and described themselves as being white (72.6\%), married or living as if (53.1\%), having children (77.6\%), Catholics (80.1\%) and regular attendants of religious services (61.2\%). Most of them had low degree (eighth grade being their highest degree) of schooling (81.5\%) and only $32.0 \%$ were employed at the moment of evaluation. Most of the patients declared themselves as economically independents (53.5\%) and $28.8 \%$ would be breadwinners by then, even though $55.1 \%$ specified low personal income (a maximum of 1 Brazilian Minimum Wage, which then corresponded to around US\$ 300) and 57.7\% also indicated low familial income (a maximum of 3 Brazilian Minimum Wages).

For these 273 male patients, the median results for the continuous variables were: 28.5 years for the average for two age bench-marks related to the onset of Problem Drinking; 7 for the number of years since the onset of problems with drinking; 8 drinks/week as actual consumption of alcoholics; 9 for the number of clinical symptoms and 4 for the number of social consequences possibly related to drinking problems listed in medical chart; 27 points as median score for the MMPI MacAndrew Scale, 63 for D Scale, 62 for PD Scale and 24.5 points for the Taylor Manifest Anxiety Scale of the MMPI.

The Cluster Analysis yielded two groups, here designated as Cluster 1 and Cluster 2, respectively constituted by 96 (35.2\%) and 177 (64.8\%) patients. Chi-Square results derived from socio-demographic comparisons indicated significant differences between these two clusters only for four economic variables - "employment status", "economic dependence of someone else", "being a breadwinner" and "personal income" (See table 2, p-values in boldface). When the 15 replicated variables of Babor's Typology were considered, results were significantly higher for patients included in Cluster 2, except for the proportion of patients who met criteria for ADS (Figure 1).

Table 3 summarizes the results of the Chi-Square Tests comparing the answers of patients included in each of these clusters and to variables identified during the development of a typology by our research group ${ }^{18}$. This tipology (Lappda Typology) was established on this same group of patients using Correspondence Analysis (applied to identify the least number of variables capable of representing the maximum variability of the subjects) and Cluster Analysis (designed to identify two subgroups). An Heuristic Analysis performed at that moment organized the 20 variables derived from initial Correspondence Analysis into three semantic sets - "feelings", "beliefs", and "behaviors". Significant differences were now found between these two Clusters and 14 of the Lappda variables and also for 2 other variables related to the designated therapeutic alternatives and to adherence to treatment also tested.

The Kappa Index yielded for the agreement analysis between the two clusters that resulted from this replication of Babor's variables and the two subgroups generated during the construction of the Lappda Typology was of 0.188 .

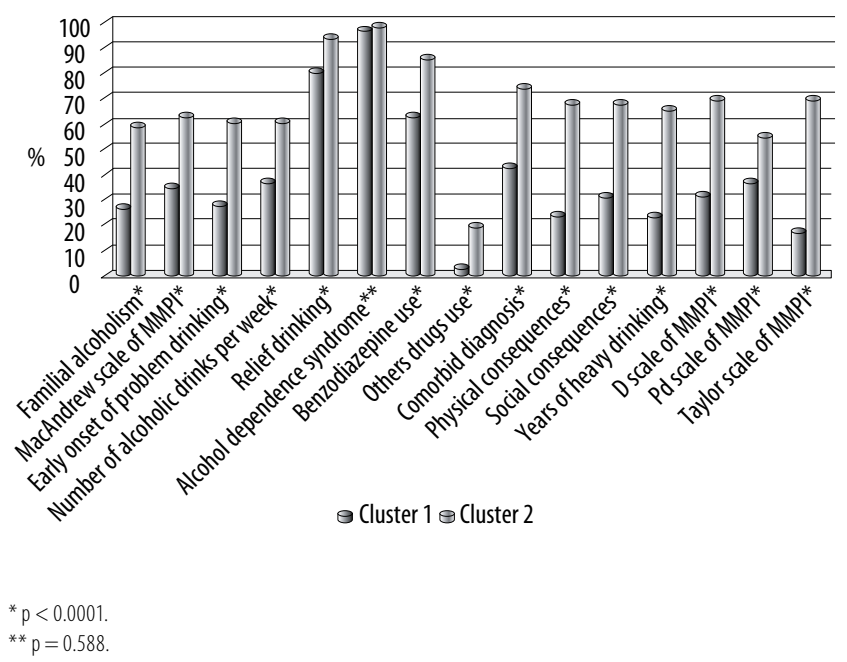

Figure 1. Bivariate Analysis between identified clusters and replication variables (for each variable, the columns indicate the percentage of answers in the categories "yes" or "above median). 
Table 3. Bivariate Analysis between identified clusters and variables related to feelings, beliefs, behaviors and treatment

\begin{tabular}{|c|c|c|c|c|}
\hline Variables & Total & $\begin{array}{c}\text { Cluster } \\
1(\%)\end{array}$ & $\begin{array}{c}\text { Cluster } \\
2(\%)\end{array}$ & p-value \\
\hline \multicolumn{5}{|c|}{ Feelings when start to drink } \\
\hline Lonely & 24.2 & 10.6 & 31.6 & $<0.001$ \\
\hline Needy & 17.0 & 8.5 & 21.6 & 0.006 \\
\hline That has done something wrong & 21.1 & 10.6 & 26.9 & 0.002 \\
\hline Incapable & 15.1 & 5.3 & 20.5 & 0.001 \\
\hline Lost & 19.2 & 9.6 & 24.6 & 0.003 \\
\hline Needing courage & 26.0 & 14.9 & 32.2 & 0.002 \\
\hline Rejected & 17.7 & 8.5 & 22.8 & 0.004 \\
\hline Abandoned & 14.0 & 8.5 & 17.0 & 0.058 \\
\hline Without prospective & 22.6 & 14.9 & 26.9 & 0.025 \\
\hline \multicolumn{5}{|c|}{ Beliefs } \\
\hline $\begin{array}{l}\text { That he suffers from psychological } \\
\text { problems }\end{array}$ & 29.5 & 20.0 & 34.7 & 0.012 \\
\hline $\begin{array}{l}\text { That Depression led him to heavy } \\
\text { drinking }\end{array}$ & 35.7 & 25.3 & 41.5 & 0.008 \\
\hline $\begin{array}{l}\text { That economic problems led him to } \\
\text { heavy drinking }\end{array}$ & 24.8 & 15.8 & 29.8 & 0.011 \\
\hline $\begin{array}{l}\text { That anxiety led him to heavy } \\
\text { drinking }\end{array}$ & 23.3 & 17.9 & 26.3 & 0.120 \\
\hline $\begin{array}{l}\text { That marital problems led him to } \\
\text { heavy drinking }\end{array}$ & 19.5 & 14.7 & 22.2 & 0.140 \\
\hline That relapses due to anxiety & 21.1 & 16.0 & 24.0 & 0.128 \\
\hline That relapses due to depression & 28.0 & 19.1 & 32.9 & 0.017 \\
\hline $\begin{array}{l}\text { That relapses due to economic } \\
\text { problems }\end{array}$ & 18.0 & 12.8 & 21.0 & 0.098 \\
\hline $\begin{array}{l}\text { That economic problems led him to } \\
\text { stop drinking }\end{array}$ & 28.5 & 24.2 & 30.8 & 0.252 \\
\hline \multicolumn{5}{|c|}{ Behaviors } \\
\hline Drinking caused problems at work & 35.6 & 21.1 & 43.6 & $<0.001$ \\
\hline $\begin{array}{l}\text { Has been involved in verbal } \\
\text { aggression }\end{array}$ & 58.2 & 43.2 & 66.5 & $<0.001$ \\
\hline \multicolumn{5}{|c|}{ Treatment } \\
\hline $\begin{array}{l}\text { Received primarily pharmacological } \\
\text { treatment }\end{array}$ & 48.2 & 33.8 & 55.5 & 0.002 \\
\hline $\begin{array}{l}\text { Adherence to treatment of above } \\
12 \text { months }\end{array}$ & 28.2 & 17.7 & 33.9 & 0.005 \\
\hline
\end{tabular}

\section{DISCUSSION}

In this alternative reconstruction of Babor's Typology, the two clusters differed in 14 of the 15 available variables - the exception being for the ADS diagnosis (see Figure 1). Given that referral criteria for the outpatient program indicated that patients with a diagnosis of Harmful Use should not be referred, it was expected that this group of patients had a more severe clinical profile than those originally studied by Babor ${ }^{4,16}$, and only three out of the 273 studied patients did not receive a diagnosis of ADS.
The characteristics of Cluster 1 patients indicate that they had a better economic and social situation: more frequently than Cluster 2 patients, they described themselves as being employed, breadwinners, economically independents and having a not so low level of income (see Table 2). Due to the study design, it is not possible to assert if an unfavorable socioeconomic status should be taken as a risk factor or a consequence of alcoholism, but these findings surely match the higher clinical severity of these patients. Indeed, besides presenting a lower socio-economic situation, Cluster 2 patients were associated with higher vulnerability and more severe clinical features: lower age of onset of problem drinking; higher frequency of familial alcoholism; higher amounts of alcohol consumption and more years of heavy drinking; higher rates of use of benzodiazepines and illicit drugs; higher rates of comorbid medical conditions; more physical and social consequences; and higher rates of depressive and anxiety symptoms and antisocial personality traits.

Evaluation and replication studies usually agree with Babor's findings in relation to the more severe subtype: higher severity of "alcohol and other substances problems", higher rates of "Chronicity and consequences of Drinking" and also of "Psychiatric Symptoms "4,8-10,15-18. The results here presented suggest that Cluster 1 patients may, in fact, be considered similar to Type A alcoholic patients (lower severity) and those included in Cluster 2 to Babor's Type B patients (higher overall severity $)^{4,16}$.

Although a correlation between heavy drinking and the development of psychiatric disorders other than alcoholism has not yet been demonstrated ${ }^{24}$, it is considered that a period of heavy drinking is essential to the development of an ADS 25 . Severe alcoholic patients often present more depressive and anxiety symptoms and tend to be more impulsive ${ }^{26}$ and their psychopathological symptoms might be either relieved or aggravated by alcohol use $\mathrm{e}^{27,28}$.

Although no definite assumption can here be made, considering the bivariate analysis between the two Clusters and variables related to the Lappda Tipology, if we focus on the statistically significant results related to beliefs (see Table 3) namely depression (and, perhaps, anxiety) leading to heavy drinking and to relapse - it is possible to admit that Cluster 2 patients consumed alcohol beverages to relieve dysfunctional mood states perceived as negative even before the development of the ADS. This assumption is somehow supported by the fact that Cluster 2 patients were significantly more likely to receive an essentially pharmacological treatment and to adhere to treatment for a longer period than patients included in Cluster 1.

The rates of Cluster 2 patients who admitted negative feelings - lonely, needy, incapable, lost, needing courage and has done something wrong - were significantly higher than those of Cluster 1 patients, as found for the more severe subgroup of the Lappda Typology ${ }^{18}$. Their prevalent "beliefs" also 
included suffering from psychological problems and that anxiety and economic aspects would be important factors favoring heavy drinking. Behavioral problems were also more frequent among these patients; and, as above indicated, most of them received a treatment that was primarily pharmacological and also had a better outcome - higher rates of sustained treatment adherence - than Cluster 1 patients.

At this point it is relevant to point out that Cluster 2 patients had a higher frequency of affirmative answers for all of the 20 LAPPDA variables, with significant results for 14 of them (Table 3). And it is also conspicuous to mention that the Lappda typology does not discriminate subgroups according to premorbid risk factors, psychiatric comorbidity and physical consequences of alcoholic use - as Babor's Typology does -, but rather stems from feelings, beliefs and behaviors related to alcohol consumption.

And considering the main objective of this study - to try to identify personality traits that may underlie Babor's subgroups in order to improve the therapeutic possibilities of this classification of ADS -, it is also critical to consider that this replication of Babor Typology had a preponderance $(65 \%)$ of patients included in the more severe subgroup, whereas for the Lappda Typology only 22\% of the patients were classified in the more severe subgroup. And also that the kappa index yielded for the agreement between the clusters here replicated and the clusters derived from the Lappda Typology was negligible (0.188).

Even though authors like Sintov et al. ${ }^{8}$ stated that the different subgroupings of the same sample of patients indicate that the clinical utility of these typologies should be questioned ${ }^{2}$, other authors that evaluated diagnostic agreement between different typologies (including Babor's) also found low agreement indexes - Kappa Index, that ranged from 0.11 to 0.37 in their study -, but the authors, besides alerting to the significance of the overlapping across many of the multivariate alcoholic subtypes and indicated that these similarities could offer us a possibility of identifying important dimensions that better differentiate individuals among problem drinker's populations ${ }^{7}$.

In short, classifications that ensure the discrimination of subtypes but do not point to the development of distinctive treatments best suited to the clinical characteristics of each subtype of patients might result clinically unsatisfactory ${ }^{29}$ or lead to a misunderstanding on the relevance of specific clinical features ${ }^{30}$, but the commonalities pointed out by Pombo and Lesch?. Any typology of alcoholism that might ensure clinical usefulness should include, among its assessment measures, personal factors that may possibly be modified by specific and effective treatment.

Although applications of Babor Typology have indicated its usefulness in matching studies ${ }^{16,31}$, subsequent development of therapeutic strategies directed to its subtypes is still limited: but this should not be considered unexpected, if we consider that some of its variables correspond to nonmodifiable aspects of the clinical construct. Alternatively, the Lappda Typology - developed by similar statistical tools (Cluster Analysis, after previous Correspondence Analysis) to those used by Babor and associates - points to personality features that, besides discriminating subtypes, could well be targeted by pharmacological or non-pharmacologic strategies that focus on differences aroused by affective, cognitive and behavioral dimensions related to alcohol consumption.

The results here presented clearly indicate that Cluster 2 - i.e., the more severe - patients were more likely to be designated to essentially pharmacologic therapy and had higher adherence rates. These apparently paradoxical results - better compliance from the more severe subgroup of patients - are in consonance to previous affirmations that ADS treatment programs that focus on comorbidity will probably lead to better outcomes $5^{6,20,24,30}$. Alcoholic patients with worse clinical and psychiatric conditions do need pharmacological treatment whereas lower severity patients - possibly without relevant comorbidity - may be assisted by less sophisticated and even by self-help programs s $^{32,33}$.

One limitation of this study raises from the fact that it was not possible to replicate two of Babor's Typology variables ("Lifetime Severity" and "Childhood Disorders") and also that it was necessary to use other similar but not identical variables. Another limitation stems from the fact that some of the data used were partially based on self-recall - especially symptoms and consumption patterns -, which may have somehow distorted the results. The cultural differences between the group of patients evaluated here and those from whom Babor Typology was derived constraints certain comparisons, as it has already been discussed by Windle and Scheidt ${ }^{10}$. As to its generalizability, one must take into consideration that all patients of this study had been referred on the assumption of an ADS diagnosis.

Nonetheless, as already pointed, research on alcoholism typologies should focus on differences and consistencies of existing classifications, aiming to isolate subtypes that might lead to more effective routine interventions. It should also be noticed that these results, besides being useful to the discussion of the effectiveness of health practices - once evaluating a "real life" situation ${ }^{34,35}$-, strengthens the usefulness of using statistical instruments grounded on clinical reasoning when tackling the typological phenomena $a^{9,20,29}$.

In conclusion, we should stress that this approximate replication study identified two distinct clusters that held similar features to those described for the Type A/Type B classification. These reproduced clusters retained connections but also revealed differences in relation to the Lappda Typology. Considering that each of the two replicated clusters seem to be associated to different personality traits - according to their correlations to the affective, cognitive and 
behavioral dimensions brought forward by the Lappda Typology -, it is reasonable to expect that these results might contribute to the development of more comprehensive and effective therapeutic strategies specifically tailored to target more specific personality traits of these subgroups of alcoholic patients, what should be the object of another study.

\section{INDIVIDUAL CONTRIBUTIONS}

All authors contributed to conception and design, analysis and interpretation of data; contributed to drafting the article and revising it critically for important intellectual content; and given the final approval of the version to be published.

\section{CONFLICTS OF INTEREST}

This article is not limited by conflicts of interest. The Study Protocol as approved by the Research Ethics Committees of HU-UFJF (099-Protocol 23/2000-Group III) and Research Ethics Committees of UFJF (1071.117.2007 Protocol).

\section{FUNDING}

Student who participated of the study at any moment received scholarships from the DSM-SUS-JF and UFJF.

\section{REFERENCES}

1. Kendler KS, Myers J, Dick D, Prescott CA. The relationship between genetic influences on alcohol dependence and on patterns of alcohol consumption. Alcohol Clin Exp Res. 2010;34(6):1058-65.

2. Leggio L, Kenna GA, Fenton M, Bonenfant E, Swift RM. Typologies of alcohol dependence. From Jellinek to genetics and beyond. Neuropsychol Rev. 2009;19(1):115-29.

3. Berenzon S, Robles R, Reed GM, Medina-Mora ME. Gender-related issues in the diagnosis and classification of alcohol use disorders among Mexican patients seeking specialized services. Rev Bras Psiquiatr. 2011;23(Supl 1):117-24.

4. Babor TF, Hofmann M, DelBoca FK, Hesselbrock V, Meyer RE, Dolinsky ZS, et al. Types of alcoholics, I. Evidence for an empirically derived typology based on indicators of vulnerability and severity. Arch Gen Psychiatry. 1992;49(8):599-608.

5. Hesselbrock VM, Hesselbrock MN. Are there empirically supported and clinically useful subtypes of alcohol dependence? Addiction. 2006;101 Suppl 1:97-103.

6. Moss HB, Chen CM, Yi HY. Prospective follow-up of empirically derived Alcohol Dependence subtypes in wave 2 of the National Epidemiologic Survey on Alcohol And Related Conditions (NESARC): recovery status, alcohol use disorders and diagnostic criteria, alcohol consumption behavior, health status, and treatment seeking. Alcohol Clin Exp Res. 2010;34(6):1073-83.

7. Pombo S, Lesch OM. The alcoholic phenotypes among different multidimensional typologies: similarities and their classification procedures. Alcohol Alcohol. 2009;44(1):46-54.

8. Sintov ND, Kendler KS, Young-Wolff KC, Walsh D, Patterson DG, Prescott CA. Empirically defined subtypes of alcohol dependence in an Irish family sample. Drug Alcohol Depend. 2010;107(2-3):230-6.

9. Babor TF, Caetano R. Subtypes of substance dependence and abuse: implications for diagnostic classification and empirical research. Addiction. 2006;101 Suppl 1:104-10.
10. Windle M, Scheidt DM. Alcoholic subtypes: are two sufficient? Addiction. 2004;99(12):1508-19.

11. Ribeiro MS, Guirro UBP, Baldi BG. Tipologias em alcoolismo: diagnóstico e terapêutica. Arq Bras Psiquiatr Neurol Med Legal. 2002;80/81:24-32.

12. Ribeiro MS, Ribeiro LC, Ferreira RA. Cluster Analysis and Heuristic Analysis in building a typology of alcoholics. J Bras Psiquiatr. 2014;63(4):299-307.

13. Ribeiro MS, Ribeiro LC, Souza GF, Antunes MG, Oliveira LN. Avaliação dos tipos 1 e 2 de alcoolismo de Cloninger em homens participantes de um programa de tratamento ambulatorial. Rev Psiquiatr Clín. 2008;35(2):39-48.

14. Pombo S, da Costa NF, Figueira ML. Are the binary typology models of alcoholism valid in polydrug abusers? Rev Bras Psiquiatr. 2015;37(1):40-8.

15. Ribeiro MS, Ribeiro LC, Souza GF, Antunes MG, Nogueira RB, Sousa KDC. Aplicabilidade da classificação de alcoolismo tipo A/tipo B. J Bras Psiquiatr. 2009;58(1):17-25.

16. Litt MD, Babor TF, DelBoca FK, Kadden RM, Cooney NL. Types of alcoholics, II. Application of an empirically derived typology to treatment matching. Arch Gen Psychiatry. 1992;49(8):609-14

17. Brown J, Babor TF, Litt MD, Kranzler HR. The type A/type B distinction. Subtyping alcoholics according to indicators of vulnerability and severity. Ann N Y Acad Sci. 1994;708:23-33.

18. Carpenter KM, Hasin DS. Reliability and discriminant validity of the Type I/II and Type A/B alcoholic subtype classifications in untreated problem drinkers: a test of the Apollonian Dionysian hypothesis. Drug Alcohol Depend. 2001;63(1):51-67.

19. Johnson EO, Pickens RW. Familial transmission of alcoholism among nonalcoholics and mild, severe, and dissocial subtypes of alcoholism. Alcohol Clin Exp Res. 2001;25:661-6.

20. Baltieri DA, Corrêa Filho JM. Role of two clusters of male alcoholics in treatment retention. Eur Addict Res. 2012;18(4):201-11.

21. Ribeiro MS, Ribeiro LC, Ferreira RA, Souza GF. Características de alcoólicos à adesão prolongada num programa ambulatório. Acta Med Port. 2010;23(6):965-72.

22. Benkö A, Simões RJP. Inventário Multifásico Minesota de Personalidade - Manual (tradução e adaptação). Rio de Janeiro: (EPA; s/d.

23. Dahlstrom WG, Welsh GS. An MMPI Handbook: a guide to use in clinical practice and research. Minneapolis: University of Minnesota Press; 1965.

24. Flensborg-Madsen T, Mortensen EL, Knop J, Becker U, Sher L, Grønbaek M. Comorbidity and temporal ordering of alcohol use disorders and other psychiatric disorders: results from a Danish register-based study. Compr Psychiatry. 2009;50(4):307-14.

25. Flensborg-Madsen T, Becker U, Grønbæk M, Knop J, Sher L, Mortensen EL. Alcohol consumption and later risk of hospitalization with psychiatric disorders: prospective cohort study. Psychiatry Res. 2011;187(1-2):214-9.

26. Marmorstein NR. Longitudinal associations between alcohol problems and depressive symptoms: early adolescence through early adulthood. Alcoholism: Clinical and Experimental Research. 2009;33(1):49-59.

27. Driessen M, Veltrup C, Wetterling T, John U, Dilling H. Axis I and axis II comorbidity in alcohol dependence and the two types of alcoholism. Alcohol Clin Exp Res. 1998;22(1):77-86.

28. Zucker RA. Alcohol use and alcohol use disorders: a developmental biopsychosocial systems formulation covering the life course. In: Cicchetti D, Cohen DJ, editors. Developmental psychopathology. New York: Wiley; 2006. p. 620-56.

29. Gunzerath L, Hewitt BG, Li TK, Warren KR. Alcohol research: past, present, and future. Ann N Y Acad Sci. 2011;1216:1-23.

30. Nordholm D, Nielsen B. Personality disorders among danish alcoholics attending outpatient treatment. Eur Addict Res. 2007:13(4):222-9.

31. Dundon W, Lynch KG, Pettinati HM, Lipkin C. Treatment outcomes in type A and B alcohol dependence 6 months after serotonergic pharmacotherapy. Alcohol Clin Exp Res. 2004;28(7):1065-73.

32. Moyer A, Finney JW, Swearingen CE, Vergun P. Brief interventions for alcohol problems: a meta-analytic review of controlled investigations in treatment-seeking and non-treatment-seeking populations. Addiction. 2002;97(3):279-92.

33. Moos RH, Moos BS. Long-term influence of duration and intensity of treatment on previously untreated individuals with alcohol use disorders. Addiction. 2003;98(3):325-7.

34. Bao Y, Duan N, Fox SA. Is some provider advice on smoking cessation better than no advice? Health Serv Res. 2006;41(6):2114-35.

35. Haro JM, Suarez D, Novick D, Brown J, Usall J, Naber D; SOHO Study Group. Three-year antipsychotic effectiveness in the outpatient care of schizophrenia: observational versus randomized studies results. Eur Neuropsychopharmacol. 2007;17(4):235-44. 